\title{
Cutaneous Lichen Amyloidosis Associated with Multiple Endocrine Neoplasia Type 2A: An Early Clinical Marker
}

\section{Dependra Narayan Singh, Sushil Gupta, Amit Agarwal}

How to cite this article: Singh DN, Gupta S, Agarwal A. Cutaneous Lichen Amyloidosis Associated with Multiple Endocrine Neoplasia Type 2A: An Early Clinical Marker. World J Endocr Surg 2012;4(1):41.

Source of support: Nil

Conflict of interest: None declared
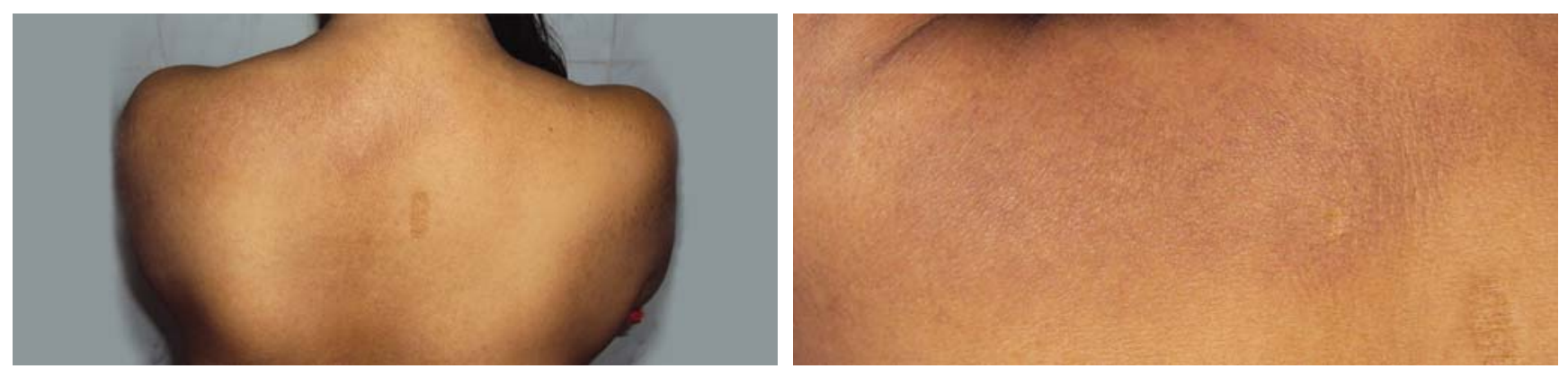

Fig. 1: A 51-year-old lady affected with multiple endocrine neoplasia type $2 A$ (MEN 2A) having bilateral adrenal pheochromocytoma (PCC), medullary thyroid carcinoma (MTC) and cutaneous lichen amyloidosis (CLA) on upper back at interscapular location more on right side

\section{CASE SUMMARY}

Pruritic, maculopapular skin lesion was noticed about 15 years before the patient noticed the classical triad of episodic headache, palpitation and increased sweating along with associated episodic hypertension. Small right thyroid lobe medullary thyroid carcinoma (MTC) was detected on evaluation. On genetic testing, she was detected to have c634 RET mutations. The patient underwent bilateral adrenalectomy and total thyroidectomy with central compartment lymph node dissection.

Multiple endocrine neoplasia (MEN) 2A-associated CLA has almost always been described in the setting of c634 RET mutations. It has been estimated that more than 30\% of patients with MEN 2A who have a c634 RET mutation will develop cutaneous lichen amyloidosis (CLA) during their lifetime. CLA may be suggestive of an association with MEN 2A; lesions have always been reported to begin at the level of the first to the fourth thoracic vertebra, extending at least from the midline to the scapula, either unilaterally or bilaterally, but sparing the lower limbs (Fig. 1). Virtually all reported cases of MEN 2A-associated CLA have featured pruritus as the initial manifestation, usually appearing within the first 2 decades of life. Signs and symptoms of CLA may be extremely subtle, but in most reported cases, the onset of CLA manifestations actually predated the diagnosis of MEN 2A. Thus, the potential of the former as a diagnostic clue for the latter is highlighted.

\section{ABOUT THE AUTHORS}

\section{Dependra Narayan Singh}

Senior Resident, Department of Breast and Endocrine Surgery, Sanjay Gandhi Postgraduate Institute of Medical Sciences, Lucknow Uttar Pradesh, India

\section{Sushil Gupta}

Professor, Department of Medical Endocrinology, Sanjay Gandhi Postgraduate Institute of Medical Sciences, Lucknow, Uttar Pradesh, India

\section{Amit Agarwal}

Professor, Department of Breast and Endocrine Surgery, Sanjay Gandhi Postgraduate Institute of Medical Sciences, Lucknow Uttar Pradesh, India

\section{Corresponding Author}

Amit Agarwal, Professor, Department of Breast and Endocrine Surgery, Sanjay Gandhi Postgraduate Institute of Medical Sciences, Raebareli Road, Lucknow-226014, Uttar Pradesh, India, Phone: +91-522-2494393, Fax: +91-522-2668078, e-mail: amit@sgpgi.ac.in 


\title{
Advertising \& Marketing
}

\section{Dedicated to Mark Your Presence in Medical Fraternity}

\author{
We Extend Our Effectual Support in Form of:
}

\section{Advertisement | Bulk Subscription | Reprints | e-Prints Online Advertisement | Customization | CME | Endorsements}

- Our tactical and conversant publishing team owns a targeted approach to aid you in designing customized market solutions to make you reach key markets and also enjoy business proliferation with our competitive pricing.

- Being world's leading, extensive medical publishers, our state-of-art products and services developed under the close association of local and international medical experts meet your marketing and educational program requirements productively.

- Our growing international associations give you a platform to experience campaign on global front.

- Our PER division includes a team of renowned doctors and specialists to undertake content management for your products and services.

\section{Explore more at:}

www.jaypeejournals.com

(11) Jaypee Brothers Medical Publishers Pvt. Ltd.

\section{Domestic \& Overseas Operations}

Ahmedabad $\bullet$ Bengaluru $\bullet$ Chennai $\bullet$ Chandigarh $\bullet$ Guwahati $\bullet$ Hyderabad $\bullet$ Kochi $\bullet$ Kolkata

$\bullet$ Lucknow $\bullet$ Mumbai $\bullet$ Mangalore $\bullet$ Nagpur $\bullet$ Patna $\bullet$ Pune $\bullet$ Vijayawada

- London (UK) • Panama City (Panama)

\section{Corporate Office}

4838/24 Ansari Road, Daryaganj, NewDelhi 110 002, India

Phone: 91-11-43574357

e-mail: advertisements@jaypeejournals.com 